\title{
Diagnosis of prostate cancer via nanotechnological approach
}

\author{
This article was published in the following Dove Press journal: \\ International Journal of Nanomedicine \\ 19 October 2015 \\ Number of times this article has been viewed
}

\section{Benedict J Kang $1,2, *$ \\ Minhong Jeun ${ }^{1,2, *}$ \\ Gun Hyuk Jang ${ }^{1,2}$ \\ Sang Hoon Song ${ }^{3}$ \\ In Gab Jeong ${ }^{3}$ \\ Choung-Soo $\mathrm{Kim}^{3}$ \\ Peter C Searson ${ }^{4}$ \\ Kwan Hyi Lee ${ }^{1,2}$}

'KIST Biomedical Research Institute, ${ }^{2}$ Department of Biomedical Engineering, Korea University of Science and Technology (UST),

${ }^{3}$ Department of Urology, Asan Medical Center, University of Ulsan College of Medicine, Seoul, Republic of Korea; ${ }^{4}$ Institute for Nanobiotechnology, Johns Hopkins University, Baltimore, MD, USA

*These authors contributed equally to this work
Correspondence: Kwan Hyi Lee Biomedical Research Institute, Korea Institute of Science and Technology (KIST), Seoul 02792, Republic of Korea Email kwanhyi@kist.re.kr

\begin{abstract}
Prostate cancer is one of the leading causes of cancer-related deaths among the Caucasian adult males in Europe and the USA. Currently available diagnostic strategies for patients with prostate cancer are invasive and unpleasant and have poor accuracy. Many patients have been overly or underly treated resulting in a controversy regarding the reliability of current conventional diagnostic approaches. This review discusses the state-of-the-art research in the development of novel noninvasive prostate cancer diagnostics using nanotechnology coupled with suggested diagnostic strategies for their clinical implication.
\end{abstract}

Keywords: bioassay, nanomaterial, nanodevice, PSA, non-PSA biomarker, bodily fluid

\section{Introduction}

As the name implies, prostate cancer originates from a gland in the male reproductive system found near the bladder. It is one of the leading causes of cancer-related deaths among Caucasian males in the USA, and it is the most commonly diagnosed form of cancer in both Europe and the USA. ${ }^{1,2}$ A statistical report predicts new cases and deaths in the USA to be 220,800 and 27,540, respectively, for 2015. As shown in Figure 1, the disease can advance to a more aggressive malignant form, which can be stratified into four discrete stages: I, II, III, and IV. Upon biopsy examination, the stages are determined and stratified according to Gleason's score method. ${ }^{3,4}$ Stages I and II are localized in the prostate gland, whereas stages III and IV exhibit regional spread to the nearby bladder and distant spread to other organs, such as liver and bone, which are far away from the prostate gland..$^{5-11}$ The prevalence of local, regional, and distant forms of the cancer is known to be $81 \%, 12 \%$, and $4 \%$, respectively. No apparent symptoms appear in stage I, but they start to show and become apparent as the disease progresses. Patients diagnosed with prostate cancer at stage I, II, or III have a high 5-year survival rate, but patients with stage IV cancer have a low 5-year survival rate of $<27 \%$, highlighting the importance of early detection.

Currently available clinical diagnostic methods for prostate cancer include biochemical assay, ${ }^{12-20}$ biopsy, ${ }^{21-27}$ digital rectal examination (DRE), ${ }^{28-32}$ and transrectal ultrasonography ${ }^{33-49}$ as described in Figure 2. Among these methods, the biochemical assay is used for initial screening. The biochemical assay measures serum - a term meaning the processed medium from whole blood - prostate-specific antigen (PSA) level where a concentration $>4 \mathrm{ng} / \mathrm{mL}$ is considered to indicate a risk of prostate cancer. ${ }^{12-20}$ Since approval by the US Food and Drug Administration (FDA) 25 years ago, it has been used as the gold standard for the initial screening of the disease.

The patients with $>4 \mathrm{ng} / \mathrm{mL}$ PSA level undergo further DRE. DRE is performed in order to inspect the prostate gland condition by examining its texture and size. 


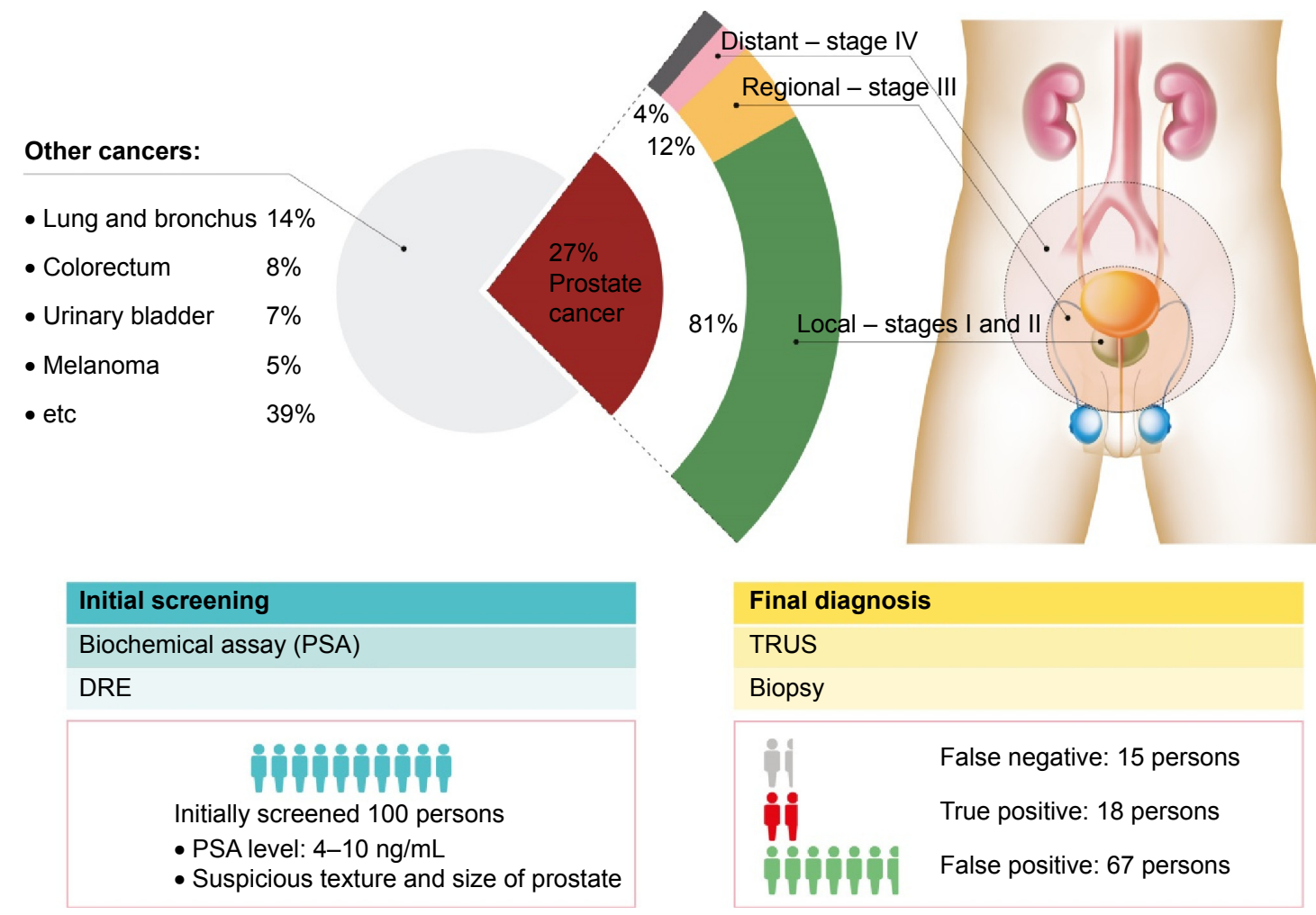

Figure I Prostate cancer diagnosis statistics.

Notes: Prostate cancer accounts for $27 \%$ of all male cancer cases meaning every one out of four men is diagnosed with prostate cancer in the USA. The localized, regional, and metastasized tumor tissue accounts for $81 \%$, $12 \%$, and $4 \%$, respectively, of all prostate cancer diagnosis with the unknown stage remaining. Typical subjects with prognoses to have prostate cancer are 85 persons per 100 persons after the initial screening, while the other 15 persons are not predicted to have prostate cancer. Only 18 persons of the 85 persons with positive initial screening result are diagnosed with prostate cancer. Surprisingly, the other 15 persons, who are believed to have no prostate cancer based on the initial screening result, are turned out to be diagnosed with prostate cancer. Data from Siegel et al.'

Abbreviations: DRE, digital rectal examination; PSA, prostate-specific antigen; TRUS, transrectal ultrasonography.

Combined with a PSA screening result, the decision is made whether to do a biopsy for further examination. However, DRE is not useful for the early detection of prostate tumor because of a possibility that a tumor could originate from the ventral or other untouchable sides of the gland..$^{28-32}$ In addition to the poor sensitivity of the examination, it is an unpleasant procedure for a patient to undergo.

After DRE patients undergo transrectal ultrasonography. It can offer a visualization of the gland for examination and can be used to guide immediate, subsequent biopsies. ${ }^{33-49}$ Upon detecting a suspicious portion of the gland, specimens are collected. Typically, 12 specimens are collected and evaluated according to the Gleason scoring system, and the most reliable, accurate diagnosis is finally made. ${ }^{21-27,50-56}$ Patients may undergo radical prostatectomy ${ }^{57}$ or hormone therapy depending on the extent of malignancy. ${ }^{58-65}$ The major drawback of a biopsy is the possibility of a potential infection caused by microbes that have migrated from the rectum which can cause inflammation in the diseased gland.
In addition to the traditional diagnostic methods, a bone scan is also carried out to scan the whole body for the presence of metastatic prostate cancer. ProstaScint- scan, positron emission tomography (PET) scanning, and computer-aided tomography (CT) with PET have all been used for prostate cancer detection. Prostate-specific membrane antigen (PSMA) has been selected as a target in the detection of prostate cancers with these techniques. ${ }^{66-72}$

A notable molecular imaging technology is 68Ga-PSMA PET/CT, which targets PSMA as the biomarker. The FDA has recently approved a clinical trial of this technology. It is the first time in the history of the development of prostate cancer diagnosis, prognosis, or monitoring, where a diagnostic tool is used to target PSMA. This technique uses an agent that is a monoclonal antibody to detect the intracellular domain of PSMA. It is possible that this agent may only capture the dead cells of the prostate cancer cells.

Despite the fact that PSA has been the gold standard for the initial screening, whether PSA screening has provided a major contribution in early prostate cancer detection remains 


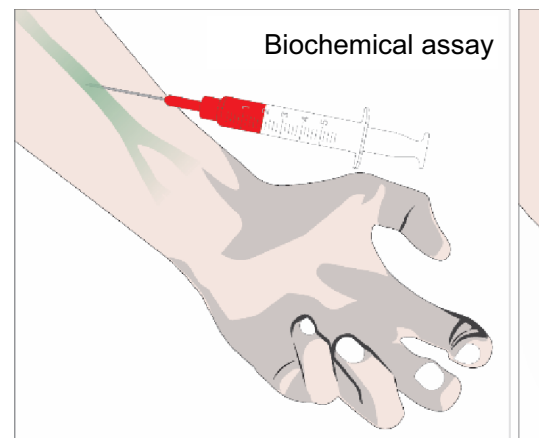

- High percentage of - False positive ( 67\%)

- False negative ( 15\%)

- The main driver leading to unnecessary biopsy

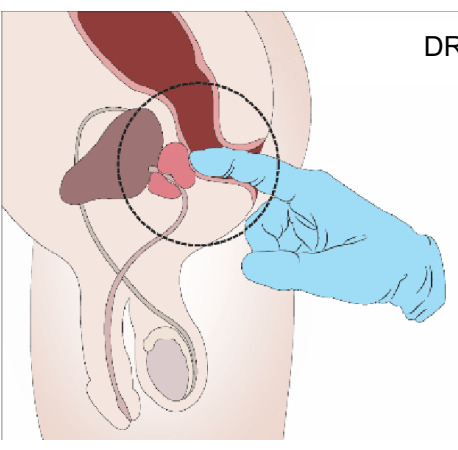

- Unpleasant procedure

- Subjectivity

- Inter- and intrapersonal variation of examiners

- Biased diagnosis
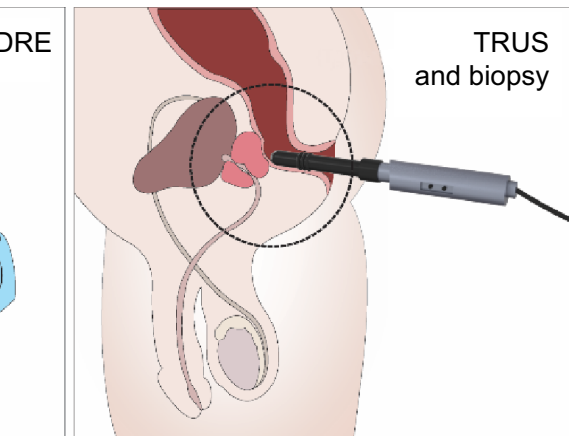

- Not patient-friendly method

- Exhausting procedure

- Unwanted side effects

- Infection caused by biopsy

- Erectile dysfunction
Current challenges

for new diagnosis

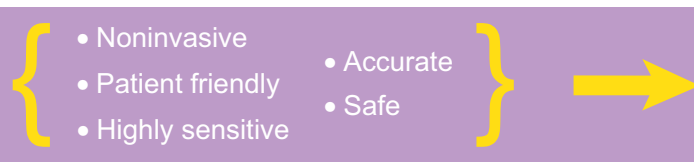

- Patient friendly

- Highly sensitive
Application of

nanotechnology

as the solution

Figure 2 Current conventional approach of prostate cancer diagnosis.

Notes: Current conventional diagnostic methodologies for the patients with prostate cancer hold several drawbacks. Patients with PSA levels $4-10$ ng/mL are subjected to further examinations. The assay gives a significant number of false positives, which raises a question of its reliability. Concurrently, DRE is performed in an initial screening for prostate cancer but introduces subjectivity to the examination. The last method is TRUS, which takes a visual image of the tumor tissue in the gland, and, in most cases, biopsies are performed with a risk of potential infections from the rectum. Due to the drawbacks of current diagnosis, a novel, noninvasive, effective, initial screening prior to diagnosis is in high demand with excellent sensitivity and accuracy.

Abbreviations: DRE, digital rectal examination; PSA, prostate-specific antigen; TRUS, transrectal ultrasonography.

uncertain. ${ }^{73,74}$ Its poor sensitivity and specificity has led to false-negative (15\%) and false-positive (66\%) diagnoses, which leads to a loss of confidence in the biomarker as an effective tool for initial screening. ${ }^{75-79}$ As a consequence, almost two-thirds of prostatic biopsies made annually in the USA and Europe are unnecessary. ${ }^{1,2}$

To circumvent the aforementioned procedures, an accurate biochemical assay is desperately needed. However, the accuracy and preciseness of the prostate cancer initial screening is currently being challenged. Inaccurate diagnoses lead to overdiagnosis or undertreatment, which exacerbates the physiological state of the tissue, makes treatment more difficult, and remains a persistent clinical problem. ${ }^{78-82}$ The inaccuracy of conventional, initial screening is largely due to the drawbacks of the biochemical assay and DRE described in Figure 2. Improvement of the diagnosis accuracy will contribute to bringing the best clinical decision to match a patient to an appropriate therapy. Thus, it is inevitable to develop a novel diagnostic strategy that will eliminate the drawbacks of the methods and accurately diagnose prostate cancer. An accurate diagnosis even at the biochemical assay level will not only minimize the complications but also maximize the efficacy of subsequent therapies for the diagnosed patients. Moreover, an earlier diagnosis also demands a more accurate probe that requires highly sensitive and specific sensors to detect highly reliable biomarkers. Thus, just like for any other diseases, an accurate diagnosis is very important for delivering the appropriate treatment to the right patient. In this regard, nanotechnology with a new biomarker for prostate cancer has been chosen as a promising tool for future noninvasive diagnosis of prostate cancer.

Nanotechnology has been employed in the development of various biomedical applications such as drug development. ${ }^{83-104}$ On the other hand, nanotechnology is also being employed for diagnostic development. ${ }^{101,103}$ The rationale for the employment of diagnostics development is to achieve a higher accuracy of diagnosis. Improvements in the sensitivity and specificity of nanotechnology are warranted and promising. ${ }^{105,106}$ Recent studies have demonstrated such improvements and suggested it as a promising tool for next-generation diagnostics, because such improvements could contribute to making a more accurate diagnosis. ${ }^{86,107-115}$

In addition to employing nanotechnology, an accurate initial screening also requires a highly reliable prostate cancer biomarker. Since biomarkers reflect the physiological state of tissue from which they are secreted, it is best to use one that is both tissue and cancer specific. PSA itself is only 
tissue specific rather than cancer specific which has resulted in controversy regarding its reliability for initial screening of prostate cancer. In order to achieve a more reliable biochemical assay other biomarkers that are specific to prostate cancer beyond PSA are highly favored. Detecting biomarkers that are specific to prostate cancer from a body fluid would make novel diagnosis less invasive and more accurate.

Herein, this review introduces the current state of nanotechnology applied toward the development of diagnostics for prostate cancer. From the standpoint of diagnostic development for prostate cancer, the relevant research trend is discussed along with clinical implications of nanotechnologybased prostate cancer detection in initial screening.

\section{From bodily fluids to nanotechnology-based bioassays Bodily fluids for noninvasive diagnosis}

Semen has become a promising proximal fluid for prostate cancer diagnosis by detecting related biomarkers and monitoring the disease's pathological process. ${ }^{116}$ Due to the fact that seminal fluids are directly transported from prostate glands, they contain more biomarkers than other fluids such as serum and urine. ${ }^{116}$

Serum is plasma after the removal of blood cells. Since all cells require oxygen that is delivered through the circulatory system, serum contains biomarkers of diseased tissues from any location of the body. Thus, serum is an outstanding source for diagnosis. However, the environment of serum is likely to hinder detection of biomarkers due in part to proteolytic degradation activity and a high concentration of albumin, which takes up to $50 \%$ of the weight of the whole serum proteome. ${ }^{117-121}$ Low-level protein biomarkers are subjected to degradation by proteases and peptidases, which divide into different classes. Typical protease classes are aspartic, cysteine-, serine-, and metallopeptidases. Peptidases belong to one of the three classes, including endo-, exo-, and carboxypeptidases. High-abundant proteins can create a masking effect by noncovalently attaching to the low-level protein biomarkers.

Urine is rich in proteome, including the biomarkers of various diseases. Since urine comes from blood through glomerular filtration, urine is in contact with the genitourinary tract that releases biomarkers of the disease. Urine has gained interest as a source or medium for diagnosis due to it being a noninvasive procedure. Many reports have demonstrated that urine contains a variety of biomarkers that could indicate diseases. ${ }^{122-126}$ Urine contains both urinary and systemic information since urine is in direct contact with urogenital organs and gets filtered from serum via glomerular filtration. Considering genitourinary organs are in direct contact with the body fluid, it is appealing to use urine for prostate cancer diagnoses in a noninvasive manner. ${ }^{127}$ However, some challenges lie in using urine as the source because of the low $\mathrm{pH}$ level, high salt concentrations, and interference from other biomarkers of higher abundance. ${ }^{128}$

\section{Reliable biomarkers and emerging nanotechnology for noninvasive diagnostic strategies}

As a source for diagnosis, various bodily fluids have been exploited because they contain metabolized biomolecules that are biomarkers of diseases. Figure 3 illustrates the typical body fluids of semen, ${ }^{116}$ serum, ${ }^{129}$ and urine. ${ }^{127,129}$ The wide variety of biomarkers from the bodily fluids indicates the body's physiological or pathophysiological state. For example, diseased tissues alter the physiological metabolisms and produce nonphysiological levels of biomolecules, enzymatic activity, or a new biomolecule species such as TMPRSS2:ERG that does not exist in the physiological state otherwise. The fusion gene is a result of a rearrangement on chromosome 21, and the TMPRSS2:ERG fusion protein is an oncogene that deregulates cytological metabolisms. ${ }^{130-144}$ The biomolecules are diverse in types, which are divided into carbohydrates, metabolites, nucleic acids, and proteins. ${ }^{127}$

The current FDA-approved biomarker PSA shows poor sensitivity and specificity and often leads to negative biopsies indicating its poor specificity in prostate cancer diagnosis. In order to compensate for the limitations of PSA as the effective biomarker for prostate cancer, novel biomarkers beyond PSA have been proposed and are under investigation. The main idea with novel biomarkers is exploiting them in conjunction with PSA. For instance, the currently FDA-approved prostate cancer gene 3 test requires urinary PSA level information so that it can generate a prostate cancer gene 3 score that would aid the diagnostic decision making. ${ }^{17,145}$ Thus, in addition to the biomarker discovery, a previous study has used panels of biomarkers for prostate cancer detection and evaluated their specificity toward prostate cancer detection. ${ }^{127}$ The trend with use of a panel of biomarkers for prostate cancer detection indicates the realization that there is no such thing as a single perfect biomarker.

The more reliable biomarkers they are, the more effective prognosis or initial screening will be. Aspiration for noninvasive patient-friendly prostate cancer detection is one of the main drivers of novel biomarker discovery from 


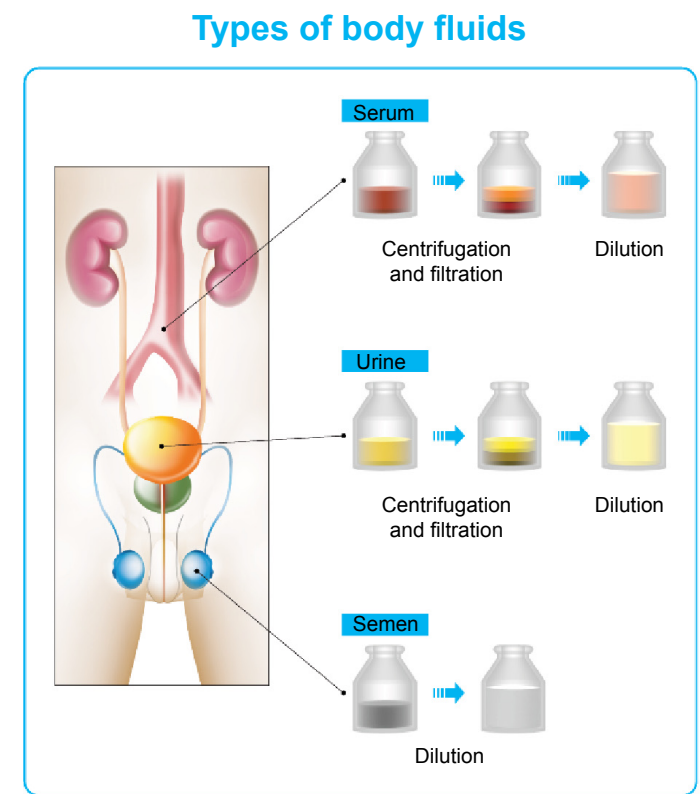

Types of biomarkers

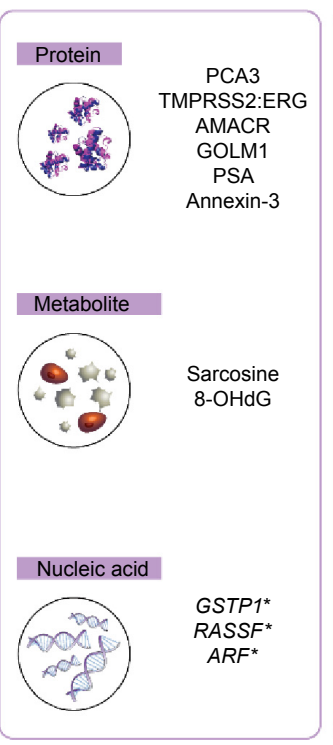

\section{Types of bioassays}

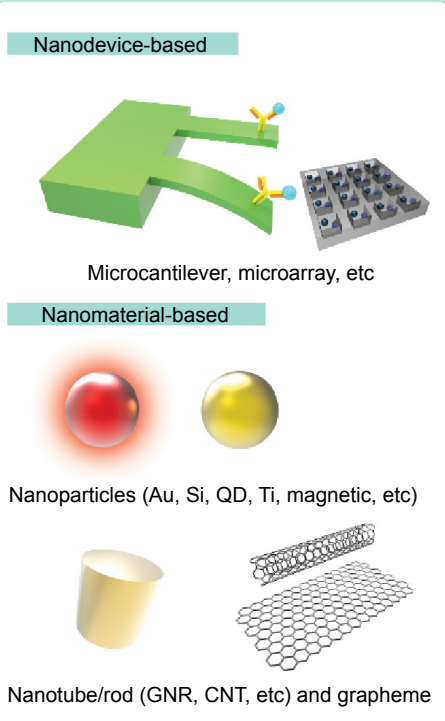

Figure 3 New diagnostic strategy based on nanotechnology (bioassay) with non-PSA biomarkers in various body fluids.

Notes: Different body fluids are subjected to appropriate sample preparations for subsequent analysis. The sample preparations are carried out to create the best environments for the nanoprobe's function. These specimens may be centrifuged and/or diluted. Various biomarkers can be collected or detected by the nanoprobes from the body fluids. Nanotechnology-based bioassays detect various prostate cancer biomarkers. The *denotes the detection of epigenetic change.

Abbreviation: PSA, prostate-specific antigen.

bodily fluids. These features will add an enormous benefit by minimizing the number of unnecessary nonpatient-friendly DRE and invasive biopsies for prognosis and diagnosis. The conventional methods, PSA assay and DRE, for initial screening put a huge burden on the patients considering the high false-positive rate of initial screening leading to unnecessary repeated biopsies.

There is no nanotechnological approach made in clinical settings, yet. Attempts are currently underway to develop bioassays with high sensitivity and specificity that could analyze bodily fluids, and nanotechnology has emerged as a promising tactical tool. However, there are challenges in detecting the novel biomarkers in body fluids. Urine, especially, has a range of different $\mathrm{pH}$ levels, high concentrations of salts, and interferences by a variety of high abundance biomolecules, which all contribute to the obstruction of detecting the desired biomarkers with low sensitivity. ${ }^{128}$ Therefore, the major tasks in the development of bioassays would be achieving a high sensitivity as well as specificity in the detection of biomarkers through nanotechnology.

\section{Highly sensitive PSA detection through nanotechnology}

As Table 1 shows, the vast majority of studies have developed various nanotechnology-based bioassays for the detection of PSA in serum, whereas only a few studies have utilized the other body fluids. The larger number of studies with serum may be attributed to the longer history of serum as a bodily fluid for diagnosis. The first nanotechnological approach for prostate cancer screening was serum detection of PSA with a cantilever. ${ }^{146}$ The sensitivity was recorded in terms of the limit of detection, and it was as low as $200 \mathrm{pg} / \mathrm{mL}$. The principle of this bioassay method is by measuring the difference in oscillation frequency between the PSA bound and unbound cantilevers.

Of all the developed nanotechnology-based bioassays, the electrochemical assay is the most popular method and has also achieved the highest sensitivity with $<0.9 \mathrm{fg} / \mathrm{mL}$ in its detection limit and $1 \mathrm{ng} / \mathrm{mL}$ being the highest. The most common material for this method is carbon nanotubes (CNT), which is the typical material for electric sensing systems. CNT is an excellent signal transducer for achieving a high sensitivity. Biomedical functionalization with the PSA antibody (anti-PSA) conjugation onto the surface of the material allowed for the detection of protein PSA in serum samples. The captured PSA alters the current that runs through the CNT giving rise to detection. ${ }^{147-159}$ Electrochemiluminescence assays took advantage of this in conjugation with the nature of titanium nanotubes to achieve a low detection limit of $1 \mathrm{fg} / \mathrm{mL} .{ }^{160}$

The most popular nanomaterial is gold either as nanoparticle or as a nanopore. Only this material has been utilized 
Table I PSA and related nanotechnology-based bioassays

\begin{tabular}{|c|c|c|c|c|}
\hline Body fluid & Method & Nanomaterial & Limit of detection & References \\
\hline Semen & ICG & CGP & I/200 dilution ${ }^{a}$ & $167-169$ \\
\hline Urine & ICG & GNP & $\mathrm{I} \mathrm{ng} / \mathrm{mL}$ & 170 \\
\hline \multirow[t]{29}{*}{ Serum } & BBA & GNP & $330 \mathrm{fg} / \mathrm{mL}$ & 172 \\
\hline & $\mathrm{RCIA}$ & & $30 \mathrm{pg} / \mathrm{mL}$ & 162 \\
\hline & CLA & $\mathrm{TiO}_{2} / \mathrm{MWCNT}$ & $800 \mathrm{fg} / \mathrm{mL}$ & 176 \\
\hline & ODI-CL & $\mathrm{Fe}_{3} \mathrm{O}_{4}^{2} \mathrm{GONP}$ & $500 \mathrm{pg} / \mathrm{mL}$ & 177 \\
\hline & EA & $\mathrm{CNT}^{4}$ & $\mathrm{I} \mathrm{ng} / \mathrm{mL}$ & 178 \\
\hline & ECA & $\mathrm{AgNP}$ & $0.9 \mathrm{fg} / \mathrm{mL}$ & 155 \\
\hline & & NPG & $750 \mathrm{pg} / \mathrm{mL}$ & 156 \\
\hline & & Pd@rGO & $10 \mathrm{pg} / \mathrm{mL}$ & 158 \\
\hline & & Ag@MSN & $15 \mathrm{pg} / \mathrm{mL}$ & 147 \\
\hline & & SNP & $760 \mathrm{pg} / \mathrm{mL}$ & 159 \\
\hline & & STV-CdSe/ZnS QD & $20 \mathrm{pg} / \mathrm{mL}$ & 150 \\
\hline & & Poly-Si NW & $<5 \mathrm{fg} / \mathrm{mL}$ & 149 \\
\hline & & MWCNTs-IL-TH & $20 \mathrm{pg} / \mathrm{mL}$ & 154 \\
\hline & & CNT & $\mathrm{l} \mathrm{ng} / \mathrm{mL}$ & 152 \\
\hline & & MWCNT-GCE & I ng/mL & 153 \\
\hline & & SWCNT & $\mathrm{l} \mathrm{ng} / \mathrm{mL}^{\mathrm{b}}$ & 148 \\
\hline & & GNPs/MWCNT-CAS & $7 \mathrm{pg} / \mathrm{mL}$ & 157 \\
\hline & & MWCNTs/IL/Chit, GNPs-PAMAM & I pg/mL & $15 \mid$ \\
\hline & ECLA & $\mathrm{Fe}_{3} \mathrm{O}_{4} @ \mathrm{SiO}_{2} \mathrm{NP}, \mathrm{Den} / \mathrm{GNP}$ & $300 \mathrm{fg} / \mathrm{mL}$ & 171 \\
\hline & & $\mathrm{CdS}-\mathrm{TiO}_{2} \mathrm{NT}, \mathrm{CdTe}-\mathrm{MWNT}$ & I fg/mL & 160 \\
\hline & & PEDOT/GR, CNS@CdTe & $800 \mathrm{fg} / \mathrm{mL}$ & 179 \\
\hline & FA & QD & $250 \mathrm{pg} / \mathrm{mL}$ & 180 \\
\hline & INPA & ENP & $830 \mathrm{fg} / \mathrm{mL}$ & 181 \\
\hline & MCA & GF & $200 \mathrm{pg} / \mathrm{mL}$ & 146 \\
\hline & NABD & GNP & I fg/mL & 166 \\
\hline & RLS & & $32 \mathrm{pg} / \mathrm{mL}$ & 164 \\
\hline & SPR & & $10 \mathrm{ng} / \mathrm{mL}$ & 165 \\
\hline & LSPCF-FOB & & $-100 \mathrm{fg} / \mathrm{mL}^{\mathrm{c}}$ & 161 \\
\hline & SERS & & $\mathrm{l} p g / \mathrm{mL}$ & 163 \\
\hline
\end{tabular}

Notes: aDiluted the sample to measure limit of detection. ${ }^{b}$ Multiplex detection. CUsed AUC to measure performance of test.

Abbreviations: AgNP, silver nanoparticle; AUC, area under the curve; Ag@MSN, silver hybridized mesoporous silica nanoparticle; BBA, bio-barcode assay; CGP, colloidal gold particle; CLA, chemiluminescence; CNS@CdTe, cadmium telluride-coated carbon nanosphere; CNT, carbon nanotube; EA, enzymatic assay; ECA, electrochemical assay; ECLA, electrochemiluminescence assay; ENP, europium(III) nanoparticle; FA, fluorescent assay; GF, gold film; GNP, gold nanoparticle; GNPs/MWCNT-CAS, gold nanoparticles enwrapped starch-cross linked multiwalled carbon nanotube; GNPs-PAMAM, gold nanoparticles-incorporated polyamidoamine dendrimer; GONP, graphene oxide nanoparticle; ICG, immunochromatography; INPA, immunometric nanoparticle-based assay; MCA, microcantilever arrays; MWCNT-GCE, multiwalled carbon nanotubemodified glassy carbon electrode; MWCNTs/IL/Chit, multiwalled carbon nanotubes/ionic liquid/chitosan; MWCNTs-IL-TH, multiwalled carbon nanotubes-ionic liquidthionine; NPG, nanoporous gold; ODI-CL, I, I0-oxalyldiimidazole chemiluminescence; Pd@rGO, palladium nanoparticle decorated-reduced graphene oxide; PEDOT/GR, poly(3,4-ethylendioxythiophene)/graphene; poly-Si NW, polycrystalline silicon nanowire; PSA, prostate-specific antigen; QD, quantum dot; RCIA, reverse colorimetric immunoassay; RLS, resonance light scattering; SERS, surface-enhanced Raman scattering; SNP, silicon nanoparticle; STV-CdSe/ZnS QD, streptavidin conjugated CdSe/ZnS quantum dot; SWCNT, single-walled carbon nanotube; $\mathrm{TiO}_{2} / \mathrm{MWCNT} \mathrm{TiO}_{2}$ nanoparticles coated multiwalled carbon nanotubes; Den, dendrimer; NABD, nucleic acid barcode dot; SPR, surface plasmon resonance; LSPCF-FOB, localized surface plasmon coupled fluorescence fiber-optic biosensor.

across all the different body fluids, indicative of its popularity in nanotechnology applications. ${ }^{151,156,157,161-172}$ However, its most popular form of use is as a nanoparticle. These nanomaterials are fabricated to obtain a high surface area to volume ratio to maximize the amount of antibodies loaded onto the material.

Although gold nanoparticles (GNPs) have been used the most in the electrochemical assay, the trend for PSA detection is to use CNT. ${ }^{148,151-154,157,173-175}$ This trend is most likely for proof of principle of the developed bioassays because CNT is primarily used for academic purposes rather than for practical use. GNP was the second most used nanomaterial, an indicative of effort to develop more sensitive PSA detection methods in serum. ${ }^{151,157,161-166,171,172}$ Unlike the CNTs, GNPs are used across various methodologies (Table 1). GNP is an excellent material for conjugation via various methods, thus it can load a high amount of targeting moieties that capture biomarkers, dye conjugates, or catalysts using its high surface area to volume ratio.

\section{Nanotechnology toward non-PSA biomarker detection}

Non-PSA biomarkers are not only protein biomolecules but also nucleic acids and other metabolites. Nucleic acids are the building blocks of DNA or RNA strands. Studies listed in Table 2 show that the nucleic acids are microRNAs, a type of RNAs. ${ }^{182,183}$ 


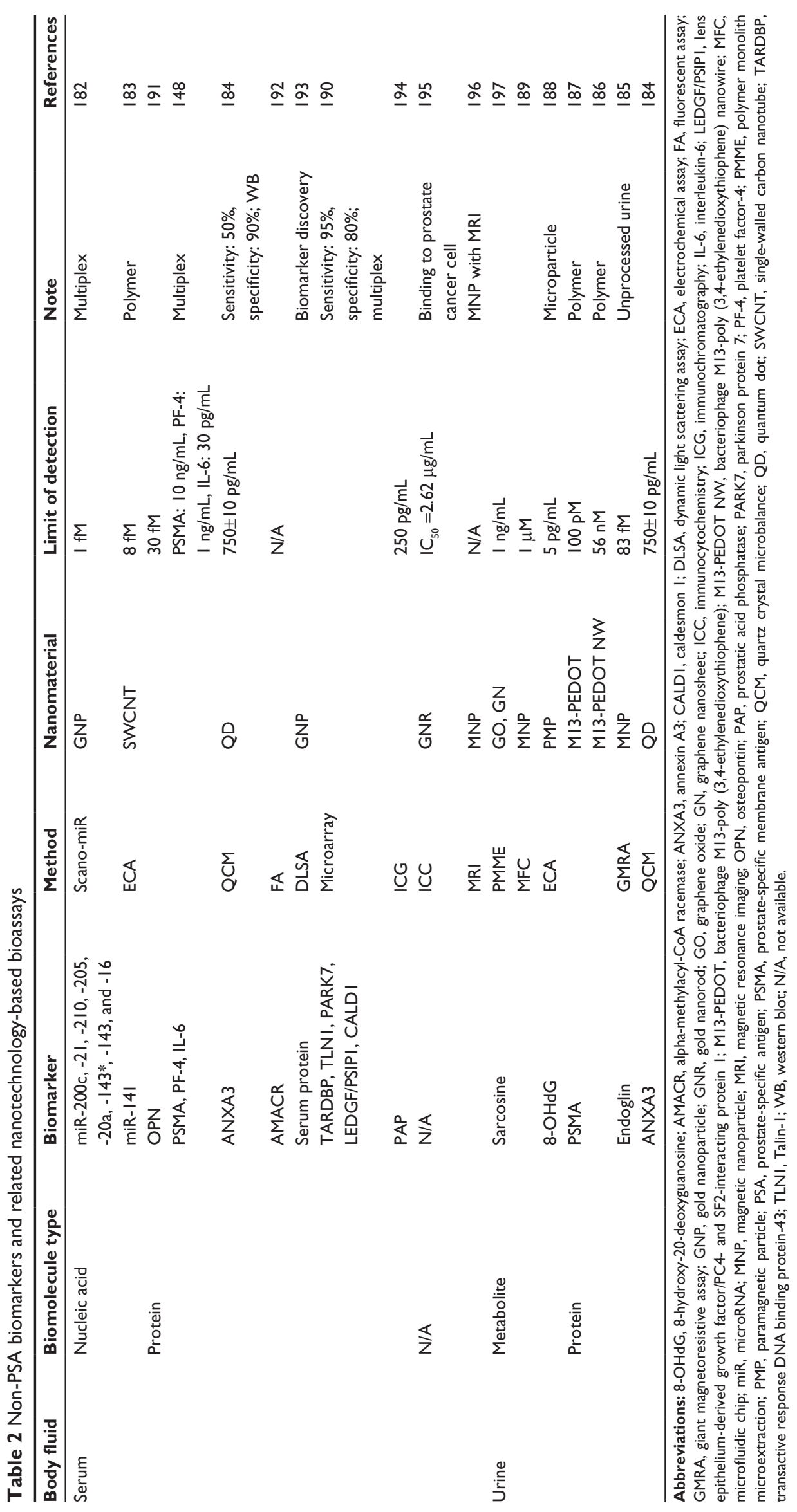


These nanotechnology-based bioassays for non-PSA biomarker detection point toward a practical use. None of these biomarkers are a good reference point for the proof of principle. The only thing that matters with these new prostate biomarkers is whether the bioassays are capable of capturing the biomarkers for detection. Effective detection ability with sufficient sensitivity and specificity in urine requires nanotechnology to achieve noninvasive initial screening. Notably, there are more studies about the detection of new non-PSA markers in urine. In response to clinical researchers, a number of studies have tried to detect non-PSA biomarkers in urine with some of the recently discovered prostate cancer biomarkers. ${ }^{184-189}$ PSMA, endoglin, and ANXA3 are the most promising biomarkers among the new ones, and the fact that they are tested with bioassays indicates how the studies are intended to show the practicality of the bioassays for initial screening.

The non-PSA biomarkers vary in type and require a different way of capturing the molecules. As with most nanomaterials, immunoassays are the most popular form of assay that is functionalized with specific antibodies against targeting biomarkers. All the studies used traditional nanomaterials as shown in Table 2. However, a novel material was used for the detection of PSMA. This nanomaterial is a nanowire that is conjugated with engineered bacteriophage M13. The unconventional nanomaterials are also used to develop new alternative assays. Rather than using traditional nanomaterials such as gold nanomaterials, quantum dots, and magnetic nanoparticles, some studies have utilized and exploited graphene and virus-based nanomaterials to achieve a more sensitive detection. ${ }^{186,187}$ The two interesting studies demonstrated the use of M13-PEDOT polymer nanowires to detect PSMA using an electrochemical assay. Another interesting study used a polymer-based nanomaterial which was a singlewalled CNT. The nanotube detected miR-141, a microRNA known as a novel prostate cancer biomarker. Like the assay method used in the studies with M13-PEDOT polymer, the electrochemical assay is used for miR-141 detection in serum. ${ }^{183,186,187}$

A unique study performed multiplex detection by using a microarray method with GNPs. This study does not present a limit of detection with the biomarkers but instead presents a unique aspect of the assay with the sensitivity and specificity for prostate cancer diagnosis. Unlike all the other studies that employed nanotechnology shown in Tables 1,2, and 3, it has a clinical implication on how it can be a promising tool for future prostate cancer diagnoses. ${ }^{190}$
Another notable fact from Table 2 is that nanotechnology-based assays can be applied for multiplexed detection. Nanotechnology is capable of detecting multiple biomarkers simultaneously. The use of a panel of prostate cancer biomarkers has been suggested for future diagnosis of prostate cancer. However, no single study has demonstrated multiplexed detection of other body fluids. ${ }^{148,182,190}$

Considering there are many DNA biomarkers for prostate cancer, more studies are warranted for a nanotechnological approach for biomarkers. Since almost all known DNA biomarkers exhibit epigenetic alteration, a sensitive nanoprobe is required. Such as alteration as a biomarker candidate for prostate cancer would add another layer of reliability to biomarker detection. Having diversified biomarkers would lead to a more accurate initial screening.

\section{Nanotechnology into device platform}

Nanotechnology-based bioassays of PSA and non-PSA biomarkers have been developed to achieve a higher sensitivity and specificity. The aforementioned techniques are built into devices to materialize new sensing platforms (Table 3). The development of the device is a convergence of nanotechnology and other sensor technologies. The main focus is to utilize nanomaterials in conjugation with traditional sensors to develop a new nanomaterial-bearing sensing device platform. This approach has led to higher sensitivity and specificity toward the detection of the prostate biomarkers, which have not been achieved without nanomaterials. The efforts to improve the properties of the devices that are intended for the detection of biomarkers from body fluids other than serum is because other body fluids - such as urine require a higher sensitivity. However, serum is the most tested bodily fluid. One of the device platforms that yielded one of the highest sensitivities is the field-effect transistor, which mainly utilized CNT as sensing nanomaterial. ${ }^{148,152,178,183,191}$ It is interesting to note that the sensitivity differs dramatically depending on the sensing nanomaterial used. Compared to CNT, polysilicon nanowires demonstrated outstanding sensitivity of $\sim 5 \mathrm{fg} / \mathrm{mL}$ of limit of detection. ${ }^{149}$ A similar device, microgapped interdigitated enzymatic assay, achieves even higher sensitivity with a $0.9 \mathrm{fg} / \mathrm{mL}$ limit of detection. ${ }^{155}$ Electrical sensing devices seem to be the most popular sensing method. An interesting aspect of this device is that the distance between the two electrodes is in the micrometer range, and there is a report of a nanogapped microelectrode array. ${ }^{155,198}$ Optical-based sensing devices such as immunochromatographic strips and quartz crystal microbalance 
Table 3 Device platforms for the nanotechnology-based bioassays

\begin{tabular}{|c|c|c|c|c|}
\hline Device & Body fluid & Nanomaterial & Limit of detection & References \\
\hline ICGS & Semen & CGP & I/200 dilution & $167-169$ \\
\hline ICGS & Serum & GNP & $250 \mathrm{pg} / \mathrm{mL}$ & 194 \\
\hline Cantilever & & GF & $200 \mathrm{pg} / \mathrm{mL}$ & 146 \\
\hline CNT network TR & & SWCNT & $\mathrm{I} \mathrm{ng} / \mathrm{mL}$ & 178 \\
\hline \multirow[t]{3}{*}{ CNT 4-electrode array } & & & $8 \mathrm{fM}$ & 183 \\
\hline & & & PSMA: 10 ng/mL, PF-4: & 148 \\
\hline & & & I ng/mL, IL-6: 30 pg/mL & \\
\hline \multirow[t]{2}{*}{ CNT FET } & & CNT & $30 \mathrm{fM}$ & 191 \\
\hline & & & $\mathrm{I} \mathrm{ng} / \mathrm{mL}$ & 152 \\
\hline Poly-Si NW FET & & Poly-Si NW & $<5 \mathrm{fg} / \mathrm{mL}$ & 149 \\
\hline MGIDEA & & $\mathrm{AgNP}$ & $0.9 \mathrm{fg} / \mathrm{mL}$ & 155 \\
\hline \multirow[t]{2}{*}{ Microarray } & & GNP & N/A & 190 \\
\hline & & & I $\mathrm{fM}$ & 182 \\
\hline QCM & & QD & $750 \pm 10 \mathrm{pg} / \mathrm{mL}$ & 184 \\
\hline QCM & Urine & QD & $750 \pm 10 \mathrm{pg} / \mathrm{mL}$ & 184 \\
\hline
\end{tabular}

Abbreviations: AgNP, silver nanoparticle; CGP, colloidal gold particle; GNP, gold nanoparticle; CNT, carbon nanotube; CNT FET, carbon nanotube field-effect transistor; GF, gold film; ICGS, Immunochromatographic strip; IL-6, interleukin-6; MGIDEA, microgapped interdigitated enzymatic assay; PF-4, platelet factor-4; poly-Si NW FET, polysilicon nanowire field-effect transistor; PSMA, prostate-specific membrane antigen; QCM, quartz crystal microbalance; QD, quantum dot; SWCNT, single-walled carbon nanotube; TR, transistor.

(QCM) exhibit a fair sensitivity in comparison to the electrical-based sensing devices. . $^{1,4,9,167-169,184}$

\section{Conclusion}

Beginning from the early 2000 s, nanotechnology has emerged as a therapeutic and diagnostic tool for the treatment and diagnosis of prostate cancer, and more studies have been accumulating since. Complications from unreliable initial screenings gave a need for researching the development of panels of novel prostate cancer biomarkers for better initial screening. Many reports have been published about the discovery of novel biomarkers. However, for the detection of some of the novel biomarkers, the initial screening requires a bioassay with a higher sensitivity and specificity while keeping it noninvasive. In response to these needs, studies have employed nanotechnology to bring forth novel bioassay development. Each of the studies has demonstrated noninvasive detection of their bioassays in one of the body fluids.

Nanotechnology is of particular interest because when we shrink the sizes of the existing materials down to the nanoscale, new distinct physical properties start to appear. As we have harnessed the properties of bulk materials, the new physical properties of nanomaterials can also be harnessed for various applications such as biomedicine. The studies aforementioned have exploited these new properties to overcome the limitations that we face with prostate cancer initial screening by significantly improving the sensitivity and specificity of biomarker detection.
Nanotechnology has proven its potential in prostate cancer biomarker detection. Nanotechnology-based bioassays have demonstrated a much higher detection sensitivity compared to the conventional enzyme-linked immunosorbent assay (ELISA) method. The higher sensitivity has much benefit because it means a stable detection - even of a trace of a biomarker. Higher sensitivity, therefore, allows for biomarker detection via urine instead of serum. The current initial screening of prostate cancer requires a blood sample for the PSA assay. It usually takes more than a drop to obtain and requires a syringe with a needle to acquire. Since this kind of operation needs a professional to carry out, the conventional method is still not enough to be patient friendly. Furthermore, the conventional method needs to be carried out by a professional, and thus, it cannot be a point-of-care for the general population to use. If we are able to take advantage of what nanotechnology can offer, it would be a great advancement in patient care because it is highly anticipated to minimize both overdiagnosis and underdiagnosis of cancer - due to its excellent specificity and sensitivity, respectively - and could monitor the disease for people at risk of recurrence after recovery.

To overcome the limitations of conventional initial screening methods, a significant number of studies proposed their nanotechnology-based bioassays. Most of the bioassays have measured biomarkers - PSA and beyond-PSAs - from serum. They outnumber the studies tested from other body fluids. Of the studies with serum, the majority of them chose PSA as the targeting biomarker. It is quite interesting to 
note that some studies are not aware of what the clinical community demands and what the exact problem with current initial screening with PSA detection is. This misunderstanding should be avoided to make further research more effective. Thus, the communication between the clinical research and nanotechnology engineering fields must be up to date at all times.

PSA has been a good reference to compare with other bioassays that have a measured PSA level. Using PSA detection as the proof of principle for their developed bioassays will not be as advantageous as before. The complications of the initial screenings turned out to be due to PSA itself being an unreliable biomarker rather than the low sensitivity of the enzyme-linked immunosorbent assay method. As the notion has grown that it is unlikely to find a perfect biomarker to diagnose a disease, PSA might still be used as one of the panel of prostate cancer biomarkers. To establish other prostate cancer biomarkers into the panel, testing the bioassay detection of the novel biomarkers is needed. However, compared to PSA, other biomarkers have less of a chance to get tested in the development of nanotechnology-based bioassays.

Clinical trials are important for the development of the bioassays in order to make them clinically relevant. Finding the cutoff value for a diagnosis or initial screening is another problem. Clinical researcher must have their attention on these nanotechnologies for the development of a more effective initial screening strategy.

Another important clinical implication is that nanotechnology-based bioassays can also contribute to monitoring the stage progression of the disease. Dynamic changes of biomarkers occur as prostate cancer develops and advances. Thus, detecting different biomarkers that represent particular stages of the disease may add an additional benefit to an accurate diagnosis. It has been reported that benign and malignant tumors must be differentiated and subjected to different treatments. Attempting to treat a benign tumor can only exacerbate the diseased state while undertreatment can also bring consequences. In that regard, aggressive stratification of the disease's stages is one of the urgent needs. To achieve this stratification, developing diagnostic tools capable of discerning the different stages of the disease could significantly improve the quality of life of the diagnosed patients by delivering an accurate treatment.

Finally, the development of nanotechnology-based bioassays is a highly interdisciplinary area that will require a robust multidisciplinary approach. Active collaboration between clinicians and experts in nanotechnology is a must in order to take development toward commercialization. It would be highly favorable for future investors and policy officials to put their interest in this area of research.

\section{Review criteria}

Pubmed and Web of Science were used in search, and the keywords were "seminal" OR "serum" OR "urine" AND "prostate cancer" AND "nano*".

\section{Acknowledgments}

We thank Suchang Mun for his graphical art contribution for this review. We are thankful of the financial support from the project grants: CTP (Convergence Technology Project at Korea Institute of Science and Technology \#2V03990) and TRC (Translational Research Center with Asan Medical Center \#2E25502).

\section{Disclosure}

The authors report no conflicts of interest in this work.

\section{References}

1. Siegel RL, Miller KD, Jemal A. Cancer statistics, 2015. CA Cancer J Clin. 2015;65:5-29.

2. Ferlay J, Steliarova-Foucher E, Lortet-Tieulent J, et al. Cancer incidence and mortality patterns in Europe: estimates for 40 countries in 2012. Eur J Cancer. 2013;49:1374-1403.

3. Humphrey PA. Gleason grading and prognostic factors in carcinoma of the prostate. Mod Pathol. 2004;17:292-306.

4. Gleason DF. Histologic grading and staging of prostatic-carcinoma. Am J Surg Pathol. 1981;5:193-193.

5. Amis ES Jr, Bigongiari LR, Bluth EI, et al. Pretreatment staging of clinically localized prostate cancer. American College of Radiology. ACR Appropriateness Criteria. Radiology. 2000;215(suppl):703-708.

6. Chung MS, Lee SH, Lee DH, Chung BH. Evaluation of the 7th American Joint Committee on cancer TNM staging system for prostate cancer in point of classification of bladder neck invasion. Jpn J Clin Oncol. 2013;43:184-188

7. Dash A, Sanda MG, Yu M, Taylor JM, Fecko A, Rubin MA. Prostate cancer involving the bladder neck: recurrence-free survival and implications for AJCC staging modification. American Joint Committee on Cancer. Urology. 2002;60:276-280.

8. Han M, Walsh PC, Partin AW, Rodriguez R. Ability of the 1992 and 1997 American Joint Committee on Cancer staging systems for prostate cancer to predict progression-free survival after radical prostatectomy for stage T2 disease. J Urol. 2000;164:89-92.

9. Iyer RV, Hanlon AL, Pinover WH, Hanks GE. Outcome evaluation of the 1997 American Joint Committee on cancer staging system for prostate carcinoma treated by radiation therapy. Cancer. 1999;85:1816-1821.

10. Taylor SH, Merriman KW, Spiess PE, Pisters L. Inadequacies of the current American Joint Committee on cancer staging system for prostate cancer. Cancer. 2006;106:559-565.

11. Zaorsky NG, Li T, Devarajan K, Horwitz EM, Buyyounouski MK. Assessment of the American Joint Committee on Cancer staging (sixth and seventh editions) for clinically localized prostate cancer treated with external beam radiotherapy and comparison with the National Comprehensive Cancer Network risk-stratification method. Cancer. 2012;118:5535-5543.

12. Moore S, Kuhrik M, Kuhrik N, Shea L. Screening for prostate cancer: PSA blood test, rectal examination, and ultrasound. Urol Nurs. 1992;12: 106-107. 
13. Crawford ED, DeAntoni EP. PSA as a screening test for prostate cancer. Urol Clin North Am. 1993;20:637-646.

14. Halperin EC. Screening for prostate cancer utilizing the prostate-specific antigen (PSA). $N$ C Med J. 1993;54:443-446.

15. Marks LS, Fradet Y, Deras IL, et al. PCA3 molecular urine assay for prostate cancer in men undergoing repeat biopsy. Urology. 2007;69:532-535.

16. Haese A, de la Taille A, van Poppel H, et al. Clinical utility of the PCA3 urine assay in European men scheduled for repeat biopsy. Eur Urol. 2008;54:1081-1088

17. Mearini E, Antognelli C, Del Buono C, et al. The combination of urine DD3(PCA3) mRNA and PSA mRNA as molecular markers of prostate cancer. Biomarkers. 2009;14:235-243.

18. Pepe P, Aragona F. PCA3 score vs PSA free/total accuracy in prostate cancer diagnosis at repeat saturation biopsy. Anticancer Res. 2011;31:4445-4449.

19. Perdonà $\mathrm{S}$, Cavadas V, Di Lorenzo G, et al. Prostate cancer detection in the "grey area" of prostate-specific antigen below $10 \mathrm{ng} / \mathrm{mL}$ : head-to-head comparison of the updated PCPT calculator and Chun's nomogram, two risk estimators incorporating prostate cancer antigen 3 . Eur Urol. 2011;59:81-87.

20. Melichar B. PSA, PCA3 and the philosophy of prostate cancer management. Clin Chem Lab Med. 2013;51:707-712.

21. Shinohara K. Improving cancer detection by prostate biopsy: the role of core number and site. Nat Clin Pract Urol. 2006;3:526-527.

22. Elabbady AA, Khedr MM. Extended 12-core prostate biopsy increases both the detection of prostate cancer and the accuracy of Gleason score. Eur Urol. 2006;49:49-53. [discussion 53].

23. Campodonico F, Casarico A, Gavazzi L, et al. Cancer detection with TRUS-guided 10-core biopsy of the prostate. an institutional assessment at the first, repeated and surgical specimen biopsy. Arch Ital Urol Androl. 2006;78:39-43.

24. Singh H, Canto EI, Shariat SF, et al. Improved detection of clinically significant, curable prostate cancer with systematic 12-core biopsy. J Urol. 2004;171:1089-1092.

25. Narayan P, Jajodia P, Stein R. Core biopsy instrument in the diagnosis of prostate cancer: superior accuracy to fine needle aspiration. $J$ Urol. 1991;145:795-797.

26. Spaander PJ, Mostofi K, Blom J. Biopsy techniques and cytology in prostate cancer. Prog Clin Biol Res. 1990;357:157-158.

27. Lee F, Littrup PJ, McLeary RD, et al. Needle aspiration and core biopsy of prostate cancer: comparative evaluation with biplanar transrectal US guidance. Radiology. 1987;163:515-520.

28. Green L. Digital rectal examination screening for prostate cancer. JAMA. 1993;270:1315. [author reply 1315-6].

29. Gerber GS, Chodak GW. Digital rectal examination in the early detection of prostate cancer. Urol Clin North Am. 1990;17:739-744.

30. Chodak GW, Keller P, Schoenberg HW. Assessment of screening for prostate cancer using the digital rectal examination. $J$ Urol. 1989;141:1136-1138.

31. Torp-Pedersen ST, Littrup PJ, Lee F, Mettlin C. Early prostate cancer: diagnostic costs of screening transrectal US and digital rectal examination. Radiology. 1988;169:351-354.

32. Chodak GW, Keller P, Schoenberg H. Routine screening for prostate cancer using the digital rectal examination. Prog Clin Biol Res. 1988;269:87-98

33. Ghai S, Toi A. Role of transrectal ultrasonography in prostate cancer. Radiol Clin North Am. 2012;50:1061-1073.

34. Kostakopoulos A, Pikraminos D, Lissiotis P, Malachias G, Stavropoulos NI, Kontothanasis D. The contribution of transrectal ultrasonography in the early diagnosis of prostate cancer. Acta Urol Belg. 1992;60:57-63.

35. Wilson TM, Guthman DA. Current status of transrectal ultrasonography in the detection of prostate cancer. Oncology (Williston Park). 1991;5:73-78. [discussion 83].

36. Hernandez AD, Smith JA Jr. Transrectal ultrasonography for the early detection and staging of prostate cancer. Urol Clin North Am. 1990; 17:745-757.
37. Fujino A, Scardino PT. Transrectal ultrasonography for prostatic cancer. II. The response of the prostate to definitive radiotherapy. Cancer. 1986;57:935-940.

38. Peeling WB, Griffiths GJ, Evans KT, Roberts EE. Diagnosis and staging of prostatic cancer by transrectal ultrasonography. A preliminary study. Br J Urol. 1979;51:565-569.

39. Huben RP, Murphy GP. Transrectal ultrasonography of the prostate and prostate cancer - an update. Appl Pathol. 1985;3:198-205.

40. Resnick MI, Willard JW, Boyce WH. Transrectal ultrasonography in the evaluation of patients with prostatic carcinoma. J Urol. 1980;124: 482-484.

41. Carpentier PJ, Schroeder FH, Blom JH. Transrectal ultrasonography in the followup of prostatic carcinoma patients. $J$ Urol. 1982;128:742-746.

42. Carpentier PJ, Schroder FH. Transrectal ultrasonography in the followup of prostatic carcinoma patients: a new prognostic parameter? J Urol. 1984;131:903-905.

43. Fujino A, Scardino PT. Transrectal ultrasonography for prostatic cancer: its value in staging and monitoring the response to radiotherapy and chemotherapy. J Urol. 1985;133:806-810.

44. Pontes JE, Eisenkraft S, Watanabe H, Ohe H, Saitoh M, Murphy GP. Preoperative evaluation of localized prostatic carcinoma by transrectal ultrasonography. J Urol. 1985;134:289-291.

45. Rifkin MD. Transrectal prostatic ultrasonography: comparison of linear array and radial scanners. J Ultrasound Med. 1985;4:1-5.

46. Devonec M. Diagnostic value of transrectal ultrasonography in prostatic cancer. Prog Clin Biol Res. 1987;243B:1-10.

47. Rorvik J, Servoll E, Halvorsen OJ. Transrectal ultrasonography in the staging of localized prostatic carcinoma. A pilot study. Scand J Urol Nephrol. 1992;26:15-19.

48. Mottet N, Lehmann M, Cicorelli S, et al. Transrectal ultrasonography in prostatic cancer: interexaminer variability of interpretation. Eur Urol. 1997;32:150-154.

49. Prakash VS, Mohan GC, Krishnaiah SV, et al. Ten-core versus 16-core transrectal ultrasonography guided prostate biopsy for detection of prostatic carcinoma: a prospective comparative study in Indian population. Prostate Int. 2013;1:163-168

50. Fowler JE Jr, Mills SE. Operable prostatic carcinoma: correlations among clinical stage, pathological stage, Gleason histological score and early disease-free survival. J Urol. 1985;133:49-52.

51. Woo S, Kaplan I, Roach M, Bagshaw M. Formula to estimate risk of pelvic lymph node metastasis from the total Gleason score for prostate cancer. J Urol. 1988;140:387.

52. Partin AW, Yoo J, Carter HB, et al. The use of prostate specific antigen, clinical stage and Gleason score to predict pathological stage in men with localized prostate cancer. J Urol. 1993;150:110-114.

53. Wolf JS Jr, Shinohara K, Carroll PR, Narayan P. Combined role of transrectal ultrasonography, Gleason score, and prostate-specific antigen in predicting organ-confined prostate cancer. Urology. 1993;42:131-137.

54. Narayan P, Gajendran V, Taylor SP, et al. The role of transrectal ultrasound-guided biopsy-based staging, preoperative serum prostatespecific antigen, and biopsy Gleason score in prediction of final pathologic diagnosis in prostate cancer. Urology. 1995;46:205-212.

55. Thickman D, Speers WC, Philpott PJ, Shapiro H. Effect of the number of core biopsies of the prostate on predicting Gleason score of prostate cancer. J Urol. 1996;156:110-113.

56. Fernandes ET, Sundaram CP, Long R, Soltani M, Ercole CJ. Biopsy Gleason score: how does it correlate with the final pathological diagnosis in prostate cancer? Br J Urol. 1997;79:615-617.

57. Jeong IG, Lim JH, You D, et al. Incremental value of magnetic resonance imaging for clinically high risk prostate cancer in 922 radical prostatectomies. J Urol. 2013;190:2054-2060.

58. Pilepich MV, Krall JM, al-Sarraf M, et al. Androgen deprivation with radiation therapy compared with radiation therapy alone for locally advanced prostatic carcinoma: a randomized comparative trial of the Radiation Therapy Oncology Group. Urology. 1995;45: 616-623. 
59. Walsh PC. Immediate versus deferred treatment for advanced prostatic cancer: initial results of the Medical Research Council Trial. The Medical Research Council Prostate Cancer Working Party Investigators Group. Br J Urol. 1997;79:235-246.

60. Bolla M, Gonzalez D, Warde P, et al. Improved survival in patients with locally advanced prostate cancer treated with radiotherapy and goserelin. N Engl J Med. 1997;337:295-300.

61. Hill B, Kyprianou N. Sequencing hormonal ablation and radiotherapy in prostate cancer: a molecular and therapeutic perspective (Review). Oncol Rep. 2002;9:1151-1156.

62. Huggins C, Hodges CV. Studies on prostatic cancer: I. The effect of castration, of estrogen and of androgen injection on serum phosphatases in metastatic carcinoma of the prostate. 1941. J Urol. 2002;168:9-12.

63. Studer UE, Hauri D, Hanselmann S, et al. Immediate versus deferred hormonal treatment for patients with prostate cancer who are not suitable for curative local treatment: results of the randomized trial SAKK 08/88. J Clin Oncol. 2004;22:4109-4118.

64. Messing EM, Manola J, Yao J, et al; Eastern Cooperative Oncology Group Study EST 3886. Immediate versus deferred androgen deprivation treatment in patients with node-positive prostate cancer after radical prostatectomy and pelvic lymphadenectomy. Lancet Oncol. 2006;7:472-479.

65. Gleave M, Klotz L, Taneja SS. The continued debate: intermittent vs continuous hormonal ablation for metastatic prostate cancer. Urol Oncol. 2009;27:81-86.

66. Ellis RJ, Kaminsky DA, Zhou EH, et al. Ten-year outcomes: the clinical utility of single photon emission computed tomography/computed tomography capromab pendetide (Prostascint) in a cohort diagnosed with localized prostate cancer. Int J Radiat Oncol Biol Phys. 2011;81:29-34.

67. Sodee DB, Conant R, Chalfant M, et al. Preliminary imaging results using In-111 labeled CYT-356 (Prostascint) in the detection of recurrent prostate cancer. Clin Nucl Med. 1996;21:759-767.

68. Shreve PD, Grossman HB, Gross MD, Wahl RL. Metastatic prostate cancer: initial findings of PET with 2-deoxy-2-[F-18]fluoro-D-glucose. Radiology. 1996;199:751-756.

69. Sanz G, Rioja J, Zudaire JJ, Berian JM, Richter JA. PET and prostate cancer. World J Urol. 2004;22:351-352.

70. Reske SN, Blumstein NM, Neumaier B, et al. Imaging prostate cancer with 11C-choline PET/CT. J Nucl Med. 2006;47:1249-1254.

71. Mintz A. PET/CT in prostate cancer: an unmet clinical need. Oncology (Williston Park). 2014;28:1065-1066.

72. Jadvar H. PSMA PET in prostate cancer. J Nucl Med. 2015;56(8): 1131-1132.

73. de Koning HJ, Schroder FH. PSA screening for prostate cancer: the current controversy. Ann Oncol. 1998;9:1293-1296.

74. McCarthy M. PSA screening said to reduce prostate-cancer deaths, or does it? Lancet. 1998;351:1563.

75. Catalona WJ, Smith DS, Ratliff TL, et al. Measurement of prostatespecific antigen in serum as a screening-test for prostate-cancer. $N$ Engl J Med. 1991;324:1156-1161.

76. Bretton PR. Prostate-specific antigen and digital rectal examination in screening for prostate cancer: a community-based study. South Med J. 1994;87:720-723.

77. Catalona WJ, Richie JP, Ahmann FR, et al. Comparison of digital rectal examination and serum prostate specific antigen in the early detection of prostate cancer: results of a multicenter clinical trial of 6,630 men. J Urol. 1994;151:1283-1290.

78. Thompson IM, Pauler DK, Goodman PJ, et al. Prevalence of prostate cancer among men with a prostate-specific antigen level $\leq 4.0 \mathrm{ng}$ per milliliter. N Engl J Med. 2004;350:2239-2246.

79. Schroder FH, van der Cruijsen-Koeter I, de Koning HJ, Vis AN, Hoedemaeker RF, Kranse R. Prostate cancer detection at low prostate specific antigen. J Urol. 2000;163:806-811.

80. Tuma RS. New tests for prostate cancer may be nearing the clinic. J Natl Cancer Inst. 2010;102:752-754.
81. Schröder FH, Hugosson J, Roobol MJ, et al; ERSPC Investigators. Screening and prostate-cancer mortality in a randomized European study. N Engl J Med. 2009;360:1320-1328.

82. Andriole GL, Crawford ED, Grubb RL 3rd, Buys SS, et al. Prostate cancer screening in the randomized prostate, lung, colorectal, and ovarian cancer screening trial: mortality results after 13 years of follow-up. J Natl Cancer Inst. 2012;104:125-132.

83. Al-Shyoukh I, Yu F, Feng J, et al. Systematic quantitative characterization of cellular responses induced by multiple signals. BMC Syst Biol. 2011;5:88

84. Hrkach J, Von Hoff D, Mukkaram Ali M, et al. Preclinical development and clinical translation of a PSMA-targeted docetaxel nanoparticle with a differentiated pharmacological profile. Sci Transl Med. 2012;4:128ra39.

85. Wong PK, Yu F, Shahangian A, Cheng G, Sun R, Ho CM. Closedloop control of cellular functions using combinatory drugs guided by a stochastic search algorithm. Proc Natl Acad Sci U S A. 2008;105: 5105-5110.

86. Dawidczyk CM, Kim C, Park JH, et al. State-of-the-art in design rules for drug delivery platforms: Lessons learned from FDA-approved nanomedicines. J Control Release. 2014;187C:133-144.

87. Ferrari M. Cancer nanotechnology: opportunities and challenges. Nat Rev Cancer. 2005;5:161-171.

88. Condon A. Designed DNA molecules: principles and applications of molecular nanotechnology. Nat Rev Genet. 2006;7:565-575.

89. Silva GA. Neuroscience nanotechnology: progress, opportunities and challenges. Nat Rev Neurosci. 2006;7:65-74.

90. Cancer nanotechnology: small, but heading for the big time. Nat Rev Drug Discov. 2007;6:174-175.

91. McCarthy N. Nanotechnology: tag teams. Nat Rev Cancer. 2011;11:537.

92. Schroeder A, Heller DA, Winslow MM, et al. Treating metastatic cancer with nanotechnology. Nat Rev Cancer. 2012;12:39-50.

93. Srikanth M, Kessler JA. Nanotechnology-novel therapeutics for CNS disorders. Nat Rev Neurol. 2012;8:307-318.

94. Errico A. New technology: nanotechnology targets cancer cells. Nat Rev Clin Oncol. 2013;10:667.

95. Harrison C. Nanotechnology: biological proteins knock nanoparticles off target. Nat Rev Drug Discov. 2013;12:264.

96. Smith DM, Simon JK, Baker JR Jr. Applications of nanotechnology for immunology. Nat Rev Immunol. 2013;13:592-605.

97. Axiak-Bechtel SM, Upendran A, Lattimer JC, et al. Gum arabic-coated radioactive gold nanoparticles cause no short-term local or systemic toxicity in the clinically relevant canine model of prostate cancer. Int J Nanomedicine. 2014;9:5001-5011.

98. Gao X, Luo Y, Wang Y, et al. Prostate stem cell antigen-targeted nanoparticles with dual functional properties: in vivo imaging and cancer chemotherapy. Int J Nanomedicine. 2012;7:4037-4051.

99. Gobin AM, Moon JJ, West JL. EphrinA1-targeted nanoshells for photothermal ablation of prostate cancer cells. Int J Nanomedicine. 2008;3:351-358.

100. Sato A, Itcho $\mathrm{N}$, Ishiguro $\mathrm{H}$, et al. Magnetic nanoparticles of $\mathrm{Fe}_{3} \mathrm{O}_{4}$ enhance docetaxel-induced prostate cancer cell death. Int J Nanomedicine. 2013;8:3151-3160.

101. Taylor RM, Sillerud LO. Paclitaxel-loaded iron platinum stealth immunomicelles are potent MRI imaging agents that prevent prostate cancer growth in a PSMA-dependent manner. Int J Nanomedicine. 2012;7:4341-4352.

102. Wu X, Ding B, Gao J, et al. Second-generation aptamer-conjugated PSMA-targeted delivery system for prostate cancer therapy. Int $J$ Nanomedicine. 2011;6:1747-1756.

103. Wu X, Tai Z, Zhu Q, et al. Study on the prostate cancer-targeting mechanism of aptamer-modified nanoparticles and their potential anticancer effect in vivo. Int J Nanomedicine. 2014;9: 5431-5440. 
104. Yuan L, Liu C, Chen Y, Zhang Z, Zhou L, Qu D. Antitumor activity of tripterine via cell-penetrating peptide-coated nanostructured lipid carriers in a prostate cancer model. Int J Nanomedicine. 2013;8:4339-4350.

105. Mouli SK, Zhao LC, Omary RA, Thaxton CS. Lymphotropic nanoparticle enhanced MRI for the staging of genitourinary tumors. Nat Rev Urol. 2010;7:84-93

106. Ma L, He S, Huang J, Cao L, Yang F, Li L. Maximizing specificity and yield of PCR by the quantum dot itself rather than property of the quantum dot surface. Biochimie. 2009;91:969-973.

107. Razzak M. Nanotechnology opens up new realm of detection in GBM. Nat Rev Clin Oncol. 2013;10:4.

108. Park H, Hwang MP, Lee KH. Immunomagnetic nanoparticle-based assays for detection of biomarkers. Int J Nanomedicine. 2013;8:4543-4552.

109. Park H, Hwang MP, Lee JW, Choi J, Lee KH. Harnessing immunomagnetic separation and quantum dot-based quantification capacities for the enumeration of absolute levels of biomarker. Nanotechnology. 2013;24:285103.

110. Hwang MP, Lee JW, Lee KE, Lee KH. Think modular: a simple apoferritin-based platform for the multifaceted detection of pancreatic cancer. ACS Nano. 2013;7:8167-8174.

111. Lee JW, Song J, Hwang MP, Lee KH. Nanoscale bacteriophage biosensors beyond phage display. Int J Nanomedicine. 2013;8:3917-3925.

112. Choi J, Park S, Stojanović Z, et al. Facile solvothermal preparation of monodisperse gold nanoparticles and their engineered assembly of ferritin-gold nanoclusters. Langmuir. 2013;29:15698-15703.

113. Galloway JF, Winter A, Lee KH, et al. Quantitative characterization of the lipid encapsulation of quantum dots for biomedical applications. Nanomedicine. 2012;8:1190-1199.

114. Lee KH, Galloway JF, Park J, et al. Quantitative molecular profiling of biomarkers for pancreatic cancer with functionalized quantum dots. Nanomedicine. 2012;8:1043-1051.

115. Park H, Lee JW, Hwang MP, Lee KH. Quantification of cardiovascular disease biomarkers via functionalized magnetic beads and on-demand detachable quantum dots. Nanoscale. 2013;5:8609-8615.

116. Drabovich AP, Saraon P, Jarvi K, Diamandis EP. Seminal plasma as a diagnostic fluid for male reproductive system disorders. Nat Rev Urol. 2014;11:278-288.

117. Thomas CE, Sexton W, Benson K, Sutphen R, Koomen J. Urine collection and processing for protein biomarker discovery and quantification. Cancer Epidemiol Biomarkers Prev. 2010;19:953-959.

118. Barratt J, Topham P. Urine proteomics: the present and future of measuring urinary protein components in disease. CMAJ. 2007; 177:361-368.

119. Zhou M, Lucas DA, Chan KC, et al. An investigation into the human serum "interactome". Electrophoresis. 2004;25:1289-1298.

120. Lopez MF, Mikulskis A, Kuzdzal S, et al. High-resolution serum proteomic profiling of Alzheimer disease samples reveals diseasespecific, carrier-protein-bound mass signatures. Clin Chem. 2005;51 1946-1954.

121. Ayache S, Panelli M, Marincola FM, Stroncek DF. Effects of storage time and exogenous protease inhibitors on plasma protein levels. Am J Clin Pathol. 2006;126:174-184.

122. Dear JW, Street JM, Bailey MA. Urinary exosomes: a reservoir for biomarker discovery and potential mediators of intrarenal signalling. Proteomics. 2013;13:1572-1580.

123. Fliser D, Novak J, Thongboonkerd V, et al. Advances in urinary proteome analysis and biomarker discovery. J Am Soc Nephrol. 2007;18: 1057-1071.

124. Nolen BM, Lokshin AE. The advancement of biomarker-based diagnostic tools for ovarian, breast, and pancreatic cancer through the use of urine as an analytical biofluid. Int J Biol Markers. 2011;26:141-152.

125. Broedbaek K, Weimann A, Stovgaard ES, Poulsen HE. Urinary 8-oxo7,8-dihydro-2'-deoxyguanosine as a biomarker in type 2 diabetes. Free Radic Biol Med. 2011;51:1473-1479.
126. Ku JH, Godoy G, Amiel GE, Lerner SP. Urine survivin as a diagnostic biomarker for bladder cancer: a systematic review. BJU Int. 2012;110:630-636.

127. Rigau M, Olivan M, Garcia M, et al. The present and future of prostate cancer urine biomarkers. Int J Mol Sci. 2013;14:12620-12649.

128. Anderson NL, Anderson NG. The human plasma proteome: history, character, and diagnostic prospects. Mol Cell Proteomics. 2002; $1: 845-867$.

129. Schacht MJ, Garnett JE, Grayhack JT. Biochemical markers in prostatic-cancer. Urol Clin North Am. 1984;11:253-267.

130. Winnes M, Lissbrant E, Damber JE, Stenman G. Molecular genetic analyses of the TMPRSS2-ERG and TMPRSS2-ETV1 gene fusions in 50 cases of prostate cancer. Oncol Rep. 2007;17:1033-1036.

131. Demichelis F, Fall K, Perner S, et al. TMPRSS2: ERG gene fusion associated with lethal prostate cancer in a watchful waiting cohort. Oncogene. 2007;26:4596-4599.

132. Clark J, Merson S, Jhavar S, et al. Diversity of TMPRSS2-ERG fusion transcripts in the human prostate. Oncogene. 2007;26: 2667-2673.

133. Yoshimoto M, Joshua AM, Chilton-Macneill S, et al. Three-color FISH analysis of TMPRSS2/ERG fusions in prostate cancer indicates that genomic microdeletion of chromosome 21 is associated with rearrangement. Neoplasia. 2006;8:465-469.

134. Chinnaiyan AM. Role of the TMPRSS2-ERG gene fusion in prostate cancer. Neoplasia. 2008;10:177-U23.

135. Cerveira N, Ribeiro FR, Peixoto A, et al. TMPRSS2-ERG gene fusion causing ERG overexpression precedes chromosome copy number changes in prostate carcinomas and paired HGPIN lesions. Neoplasia. 2006;8:826-832.

136. Lapointe J, Kim YH, Miller MA, et al. A variant TMPRSS2 isoform and ERG fusion product in prostate cancer with implications for molecular diagnosis. Mod Pathol. 2007;20:467-473.

137. Nam RK, Sugar LM, Klotz LH, Venkateswaran V, Seth A. Expression of TMPRSS2: ERG gene fusion in prostate cancer cells is an important prognostic factor for cancer progression. J Urol. 2007; 177:467-468.

138. Soller MJ, Elfving P, Lundgren R, Panagopols I. Confirmation of the high frequency of the TMPRSS2/ERG fusion gene in prostate cancer. Genes Chromosomes Cancer. 2006;45:717-719.

139. Wang JH, Cai Y, Ren CX, Ittmann M. Expression of variant TMPRSS2/ERG fusion messenger RNAs is associated with aggressive prostate cancer. Cancer Res. 2006;66:8347-8351.

140. Perner S, Demichelis F, Beroukhim R, et al. TMPRSS2: ERG fusionassociated deletions provide insight into the heterogeneity of prostate cancer. Cancer Res. 2006;66:8337-8341.

141. Iljin K, Wolf M, Edgren H, et al. TMPRSS2 fusions with oncogenic ETS factors in prostate cancer involve unbalanced genomic rearrangements and are associated with $\mathrm{HDAC} 1$ and epigenetic reprogramming. Cancer Res. 2006;66:10242-10246.

142. Hermans KG, van Marion R, van Dekken H, Jenster G, van Weerden WM, Trapman J. TMPRSS2: ERG fusion by translocation or interstitial deletion is highly relevant in androgen-dependent prostate cancer, but is bypassed in late-stage androgen receptor-negative prostate cancer. Cancer Res. 2006;66:10658-10663.

143. Perner S, Mosquera JM, Demichelis F, et al. TMPRSS2-ERG fusion prostate cancer: an early molecular event associated with invasion. Am J Surg Pathol. 2007;31:882-888.

144. Kannan K, Coarfa C, Rajapakshe K, et al. CDKN2D-WDFY2 is a cancer-specific fusion gene recurrent in high-grade serous ovarian carcinoma. PLoS Genet. 2014;10:e1004216.

145. Hessels D, Schalken JA. The use of PCA3 in the diagnosis of prostate cancer. Nat Rev Urol. 2009;6:255-261.

146. Wu G, Datar RH, Hansen KM, Thundat T, Cote RJ, Majumdar A. Bioassay of prostate-specific antigen (PSA) using microcantilevers Nat Biotechnol. 2001;19:856-860. 
147. Wang H, Zhang Y, Yu H, et al. Label-free electrochemical immunosensor for prostate-specific antigen based on silver hybridized mesoporous silica nanoparticles. Anal Biochem. 2013;434:123-127.

148. Chikkaveeraiah BV, Bhirde A, Malhotra R, Patel V, Gutkind JS, Rusling JF. Single-wall carbon nanotube forest arrays for immunoelectrochemical measurement of four protein biomarkers for prostate cancer. Anal Chem. 2009;81:9129-9134.

149. Huang YW, Wu CS, Chuang CK, et al. Real-time and label-free detection of the prostate-specific antigen in human serum by a polycrystalline silicon nanowire field-effect transistor biosensor. Anal Chem. 2013;85:7912-7918.

150. Kokkinos C, Economou A, Petrou PS, Kakabakos SE. Microfabricated tin-film electrodes for protein and DNA sensing based on stripping voltammetric detection of $\mathrm{Cd}(\mathrm{II})$ released from quantum dots labels. Anal Chem. 2013;85:10686-10691.

151. Kavosi B, Salimi A, Hallaj R, Amani K. A highly sensitive prostatespecific antigen immunosensor based on gold nanoparticles/PAMAM dendrimer loaded on MWCNTS/chitosan/ionic liquid nanocomposite. Biosens Bioelectron. 2014;52:20-28.

152. Kim JP, Lee BY, Lee J, Hong S, Sim SJ. Enhancement of sensitivity and specificity by surface modification of carbon nanotubes in diagnosis of prostate cancer based on carbon nanotube field effect transistors. Biosens Bioelectron. 2009;24:3372-3378.

153. Panini NV, Messina GA, Salinas E, Fernandez H, Raba J. Integrated microfluidic systems with an immunosensor modified with carbon nanotubes for detection of prostate specific antigen (PSA) in human serum samples. Biosens Bioelectron. 2008;23:1145-1151.

154. Salimi A, Kavosi B, Fathi F, Hallaj R. Highly sensitive immunosensing of prostate-specific antigen based on ionic liquid-carbon nanotubes modified electrode: application as cancer biomarker for prostate biopsies. Biosens Bioelectron. 2013;42:439-446.

155. Huang Y, Wang TH, Jiang JH, Shen GL, Yu RQ. Prostate specific antigen detection using microgapped electrode array immunosensor with enzymatic silver deposition. Clin Chem. 2009;55:964-971.

156. Pandey B, Demchenko AV, Stine KJ. Nanoporous gold as a solid support for protein immobilization and development of an electrochemical immunoassay for prostate specific antigen and carcinoembryonic antigen. Microchim Acta. 2012;179:71-81.

157. Tian JN, Huang JL, Zhao YC, Zhao SL. Electrochemical immunosensor for prostate-specific antigen using a glassy carbon electrode modified with a nanocomposite containing gold nanoparticles supported with starch-functionalized multi-walled carbon nanotubes. Microchim Acta. 2012;178:81-88

158. Kumar V, Srivastava S, Umrao S, Yadav RK, Nath G, Sumana G. Nanostructured palladium-reduced graphene oxide platform for high sensitive, label free detection of a cancer biomarker. RSC Adv. 2014;4:2267-2273.

159. Qu B, Chu X, Shen G, Yu R. A novel electrochemical immunosensor based on colabeled silica nanoparticles for determination of total prostate specific antigen in human serum. Talanta. 2008;76:785-790.

160. Tian CY, Zhao WW, Wang J, Xu JJ, Chen HY. Amplified quenching of electrochemiluminescence from $\mathrm{CdS}$ sensitized $\mathrm{TiO} 2$ nanotubes by CdTe-carbon nanotube composite for detection of prostate protein antigen in serum. Analyst. 2012;137:3070-3075.

161. Chang YF, Hung SH, Lee YJ, et al. Discrimination of breast cancer by measuring prostate-specific antigen levels in women's serum. Anal Chem. 2011;83:5324-5328.

162. Gao Z, Xu M, Hou L, Chen G, Tang D. Magnetic bead-based reverse colorimetric immunoassay strategy for sensing biomolecules. Anal Chem. 2013;85:6945-6952.

163. Grubisha DS, Lipert RJ, Park HY, Driskell J, Porter MD. Femtomolar detection of prostate-specific antigen: an immunoassay based on surface-enhanced Raman scattering and immunogold labels. Anal Chem. 2003;75:5936-5943.
164. Chen Z, Lei Y, Chen X, Wang Z, Liu J. An aptamer based resonance light scattering assay of prostate specific antigen. Biosens Bioelectron. 2012;36:35-40.

165. Huang L, Reekmans G, Saerens D, et al. Prostate-specific antigen immunosensing based on mixed self-assembled monolayers, camel antibodies and colloidal gold enhanced sandwich assays. Biosens Bioelectron. 2005;21:483-490.

166. Kong XL, Qi H, Zhou HX, Ren LL, Deng CY, Li FR. A novel sensitive immunoassay by nucleic acid barcode dot and its application in the detection of prostate-specific antigen. Clin Chem Lab Med. 2010; 48:279-283.

167. Sato I, Sagi M, Ishiwari A, Nishijima H, Ito E, Mukai T. Use of the "SMITEST" PSA card to identify the presence of prostate-specific antigen in semen and male urine. Forensic Sci Int. 2002;127: 71-74.

168. Sato I, Barni F, Yoshiike M, et al. Applicability of Nanotrap Sg as a semen detection kit before male-specific DNA profiling in sexual assaults. Int J Legal Med. 2007;121:315-319.

169. Sato I, Kojima K, Yamasaki T, et al. Rapid detection of semenogelin by one-step immunochromatographic assay for semen identification. J Immunol Methods. 2004;287:137-145.

170. Yuhi T, Nagatani N, Endo T, et al. Resin-based micropipette tip for immunochromatographic assays in urine samples. J Immunol Methods. 2006;312:54-60.

171. Ge SG, Yu JH, Jiao XL, Chen DR. Ultrasensitive electrochemiluminescence immunoassay for protein specific detection based on dendrimer-encapsulated gold nanoparticles labels. J Inorg Organomet Polym Mater. 2013;23:1113-1121.

172. Thaxton CS, Elghanian R, Thomas AD, et al. Nanoparticle-based bio-barcode assay redefines "undetectable" PSA and biochemical recurrence after radical prostatectomy. Proc Natl Acad Sci U S A. 2009;106:18437-18442.

173. Liao KT, Cheng JT, Li CL, Liu RT, Huang HJ. Ultra-sensitive detection of mutated papillary thyroid carcinoma DNA using square wave stripping voltammetry method and amplified gold nanoparticle biomarkers. Biosens Bioelectron. 2009;24:1899-1904.

174. Gonzalez-Garcia MB, Fernandez-Sanchez C, Costa-Garcia A. Colloidal gold as an electrochemical label of streptavidin-biotin interaction. Biosens Bioelectron. 2000;15:315-321.

175. Dequaire M, Degrand C, Limoges B. An electrochemical metalloimmunoassay based on a colloidal gold label. Anal Chem. 2000;72: 5521-5528.

176. Li W, Ge S, Wang S, Yan M, Ge L, Yu J. Highly sensitive chemiluminescence immunoassay on chitosan membrane modified paper platform using $\mathrm{TiO} 2$ nanoparticles/multiwalled carbon nanotubes as label. Luminescence. 2013;28:496-502.

177. Choi HK, Lee JH. Role of magnetic Fe3O4 graphene oxide in chemiluminescent aptasensors capable of sensing tumor markers in human serum. Anal Methods. 2013;5:6964-6968

178. Briman M, Artukovic E, Zhang L, Chia D, Goodglick L, Gruner G. Direct electronic detection of prostate-specific antigen in serum. Small. 2007;3:758-762.

179. Li WP, et al. Electropolymerized poly(3,4-ethylendioxythiophene)/ graphene composite film and its application in quantum dots electrochemiluminescence immunoassay. J Inorg Organomet Polym Mater. 2013;23:719-725.

180. Kerman K, Endo T, Tsukamoto M, Chikae M, Takamura Y, Tamiya E. Quantum dot-based immunosensor for the detection of prostatespecific antigen using fluorescence microscopy. Talanta. 2007;71: 1494-1499.

181. Huhtinen P, Soukka T, Lovgren T, Harma H. Immunoassay of total prostate-specific antigen using europium(III) nanoparticle labels and streptavidin-biotin technology. J Immunol Methods. 2004;294: 111-122. 
182. Alhasan AH, Kim DY, Daniel WL, et al. Scanometric MicroRNA array profiling of prostate cancer markers using spherical nucleic acid-gold nanoparticle conjugates. Anal Chem. 2012;84:4153-4160.

183. Tran HV, Piro B, Reisberg S, Tran LD, Duc HT, Pham MC. Labelfree and reagentless electrochemical detection of microRNAs using a conducting polymer nanostructured by carbon nanotubes: application to prostate cancer biomarker miR-141. Biosens Bioelectron. 2013;49:164-169.

184. Kim YJ, Rahman MM, Lee JJ. Ultrasensitive and label-free detection of annexin A3 based on quartz crystal microbalance. Sensor Actuat B Chem. 2013;177:172-177.

185. Srinivasan B, Li Y, Jing Y, Xing C, Slaton J, Wang JP. A three-layer competition-based giant magnetoresistive assay for direct quantification of endoglin from human urine. Anal Chem. 2011;83:2996-3002.

186. Arter JA, Diaz JE, Donavan KC, Yuan T, Penner RM, Weiss GA. Virus-polymer hybrid nanowires tailored to detect prostate-specific membrane antigen. Anal Chem. 2012;84:2776-2783.

187. Mohan K, Donavan KC, Arter JA, Penner RM, Weiss GA. Subnanomolar detection of prostate-specific membrane antigen in synthetic urine by synergistic, dual-ligand phage. J Am Chem Soc. 2013;135:7761-7767.

188. Zitka O, Krizkova S, Krejcova L, et al. Microfluidic tool based on the antibody-modified paramagnetic particles for detection of 8-hydroxy2 '-deoxyguanosine in urine of prostate cancer patients. Electrophoresis. 2011;32:3207-3220.

189. Zitka O, Cernei N, Heger Z, et al. Microfluidic chip coupled with modified paramagnetic particles for sarcosine isolation in urine. Electrophoresis. 2013;34:2639-2647.
190. O’Rourke DJ, DiJohnson DA, Caiazzo RJ Jr, et al. Autoantibody signatures as biomarkers to distinguish prostate cancer from benign prostatic hyperplasia in patients with increased serum prostate specific antigen. Clin Chim Acta. 2012;413:561-567.

191. Lerner MB, D'Souza J, Pazina T, et al. Hybrids of a genetically engineered antibody and a carbon nanotube transistor for detection of prostate cancer biomarkers. ACS Nano. 2012;6:5143-5149.

192. Gao X, Zhang H, Li Y, Su X. Mn-doped ZnSe d-dots-based alphamethylacyl-CoA racemase probe for human prostate cancer cell imaging. Anal Bioanal Chem. 2012;402:1871-1877.

193. Huo Q, Litherland SA, Sullivan S, Hallquist H, Decker DA, RiveraRamirez I. Developing a nanoparticle test for prostate cancer scoring. J Transl Med. 2012;10:44.

194. Fang C, Chen Z, Li L, Xia J. Barcode lateral flow immunochromatographic strip for prostate acid phosphatase determination. J Pharm Biomed Anal. 2011;56:1035-1040.

195. Chanda N, Shukla R, Katti KV, Kannan R. Gastrin releasing protein receptor specific gold nanorods: breast and prostate tumor avid nanovectors for molecular imaging. Nano Lett. 2009;9:1798-1805.

196. Harisinghani MG, Barentsz J, Hahn PF, et al. Noninvasive detection of clinically occult lymph-node metastases in prostate cancer. $N$ Engl J Med. 2003;348:2491-2499.

197. Tong S, Zhou X, Zhou C, et al. A strategy to decorate porous polymer monoliths with graphene oxide and graphene nanosheets. Analyst. 2013;138:1549-1557.

198. Fan Y, Chen X, Trigg AD, Tung CH, Kong J, Gao Z. Detection of microRNAs using target-guided formation of conducting polymer nanowires in nanogaps. J Am Chem Soc. 2007;129:5437-5443.
International Journal of Nanomedicine

\section{Publish your work in this journal}

The International Journal of Nanomedicine is an international, peerreviewed journal focusing on the application of nanotechnology in diagnostics, therapeutics, and drug delivery systems throughout the biomedical field. This journal is indexed on PubMed Central, MedLine, CAS, SciSearch $®$, Current Contents $\AA /$ Clinical Medicine,

\section{Dovepress}

Journal Citation Reports/Science Edition, EMBase, Scopus and the Elsevier Bibliographic databases. The manuscript management system is completely online and includes a very quick and fair peer-review system, which is all easy to use. Visit http://www.dovepress.com/ testimonials.php to read real quotes from published authors. 